\title{
Experimental Study of Various Parameters during Speed Control of Three-phase Induction Motor Using GPIC and LabVIEW
}

\author{
Adnan Ahmed, Abdul Majeed Shaikh*, Muhammad Fawad Shaikh, Shoaib Ahmed \\ Shaikh and Jahangir Badar Soomro \\ Sukkur IBA University, Sindh, Pakistan \\ Adnan.be17@iba-suk.edu.pk; amajeed.mees19@iba-suk.edu.pk; muhammadfawad@iba-suk.edu.pk; \\ shoaibahmed@iba-suk.edu.pk; jahangir.soomro@iba-suk.edu.pk \\ ${ }^{*}$ Correspondence: amajeed.mees19@iba-suk.edu.pk
}

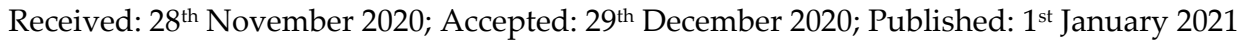

Abstract: Induction motors are widely used from home to industrial applications. Speed of induction motor plays important role, so to control the speed of induction motor various techniques are adopted and one of these techniques is $\mathrm{V} / \mathrm{F}$ control, which is adopted in this paper. This technique helps to control the speed in open control system in RPM. Moreover, Control is designed in LabVIEW, it is quite helpful to develop the circuit graphically and code is automatically written in the background to run on Field Programmable Gate Array (FPGA). The aim of this research is to study the impacts on diverse parameters during speed control of three phase induction machine with manipulation of GPIC. Solar technology is used as input source to drive the General-Purpose Inverter Controller (GPIC). Apart of this, impacts of modulation index and carrier frequency influencing the active, reactive and apparent power, temperature and power quality and current overshoot is analysed. MATLAB/Simulink and LabVIEW tools are used for simulation and results along with GPIC, Induction motor and solar panel as hardware.
\end{abstract}

Keywords: GPIC; LabVIEW; Modulation Index; Power Quality; Speed control; V/f control

\section{Introduction}

Three phase induction motors are mainly utilized in industrial applications due to low cost and better operating efficiency. Earlier, there were numerous drawbacks on the adjustable speed drives like, lower efficiency, greater size and less speed. Power electronic converters made it possible to improve the reliability, performance and accuracy [1-2]. The developments in microprocessors and power electronics allow advanced induction machine mechanisms, including field-oriented control, slip frequency regulation to be implemented [3].

In modern machines it became possible to control the speed by taking frequency and voltage parameters into the account. AC to DC transformation is performed by the inverter with reasonable voltage and frequency. During this process ripples appears at the output and these ripples are removed with the help of filter [4]. Pulse width modulation (PWM) is a technique where the pulse width is altered according to time to regulate power [5]. It is possible to manage the electrical equipment by utilizing suitable controllers likewise integrated circuits are the one of the best 
examples. In addition to this PWM technique appropriately deals with the circumstances where turn on and turn off of the power is the key requirement. It also offers reduced noise, less harmonics, and minimum power losses [6].

Several techniques are adopted to control the speed of three phase induction motors and variable frequency drive is one of them. With Sinusoidal Pulse Width Modulation (SPWM) technique it became possible to regulate the speed of three phase induction machine and that was impossible to control directly [7-8]. According to [9], frequency is directly proportional to the speed, so by regulating the frequency speed can be controlled. Programmable Logic Control (PLC) has also its significance while controlling the speed of three phase induction machine [10], it performs executions of programs written in ladder logic and then refer to Variable Frequency Drive (VFD) for governing the speed. In addition to this, with PLC speed of many induction machines can be controlled easily [11].

Energy plays an important role in all the parts of power system network [12]. Photovoltaic become the prominent source of energy to utilize. There are also other renewable sources of renewable energy like wind, biomass, geo thermal energy, besides solar energy is widely utilized due to its availability in the atmosphere. There are no any mechanical parts to move in this technology hence it is recommended to use more and more [13-14]. Lab view and MATLAB software keeps vital role in industrial applications [15]. According to [16], speed of induction motor is controlled by combination of space vector pulse width modulation and hysteresis space vector pulse width modulation, meanwhile efficiency of induction motor is evaluated with load variation. However, current signals are rebuilt because it contains ripples so these currents are improved by $65 \%$ and MATLAB software is only used to carry out the simulation work. Besides, results of current are taken with hysteresis SVWPM and HSVPWM techniques. But our work is focussed on the magnitude of different parameters during speed control of induction machine and space vector pulse width modulation technique is used. Moreover, the output of the inverter in our study is totally dependent on modulation index and up to certain value the quality of the signal is improved. General purpose inverter controller (GPIC) is used to control the speed of induction motor. Finally, when the speed of induction motor is suddenly increases, large inrush current flow and that is not good for the motor health, with this temperature increases and insulation may damage, so to control this current conduction is done in LabVIEW code for protection.

In this study, speed of induction motor is controlled by varying the carrier frequency and modulation index. Due to the variation in modulation index and carrier frequency other parameters like, power quality, active power, reactive power, apparent power, power factor and temperature are affected. In addition to this, change in magnitude of these parameters is studied. Section 2 describes the general-purpose inverter control specification and connections. In section 3 experimental setup of the proposed model is illustrated. Section 4 depicts co-simulation LabVIEW, LabVIEW Graphical User Interface (GUI) for V/F control implementation and design of Sinusoidal Pulse Width Modulation (SPWM) controller in MATLAB. Open loop control for three phase induction motor, effect of carrier frequency on voltage and current, modulation index, closed loop Control for three phase induction motor, and system with a fault are analysed and discussed in detail in section 5 . Section 6 concludes the whole research work.

\section{General Purpose Inverter Controller (GPIC)}

GPIC is embedded system device which is widely utilized in power conversion applications. This module is intended for power electronic analysis applications with very accurate performance and consistency. It can be suitable for Alternating Current (AC) to Direct Current (DC), DC to AC, $A C$ to AC, and DC to DC converters. General-Purpose Inverter Controller (GPIC) includes different type of inverters like Insulated Gate Bipolar Junction Transistor (IGBT), bridge rectifiers. It can be 
operated at two dc voltages i.e., $12 \mathrm{~V}$ and $15 \mathrm{~V}^{1,2}$. GPIC is shown in Fig. 1. Solar panel is utilized to supply $12 \mathrm{~V}$ DC to drive the GPIC.

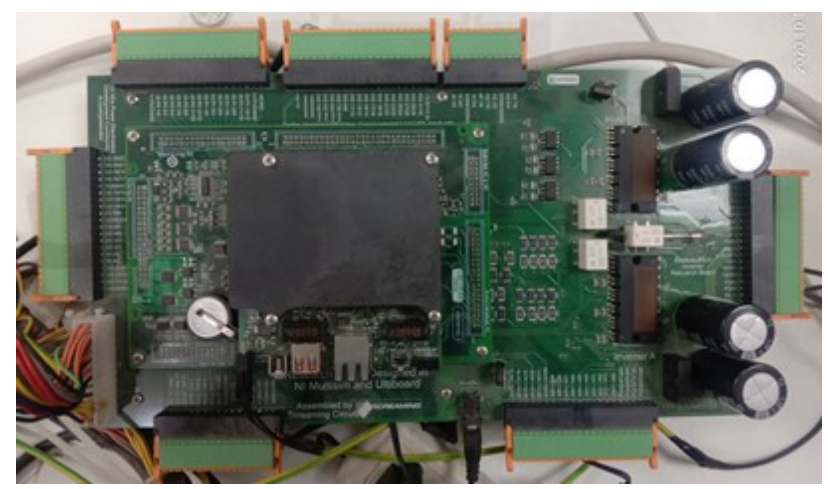

Figure 1. General Purpose inverter Controller

\section{Experimental Setup of Proposed Model}

Fig. 2 shows the wiring contacts of three phase induction machine with GPIC. First, ethernet cable is used to provide communication between general purpose inverter controller and computer. Second, photovoltaic solar panel delivers the power to GPIC, this photovoltaic (PV) panel supplies 12V DC to GPIC, Third, GPIC supplies $12 \mathrm{~V}$ to Single Board Reconfigurable input output (SbRIO) board. Fourth connection is from general purpose inverter controller to the three-phase induction machine. Fifth connection represents the encoder connection which is between motor and the board. Sixth connection represents the supply of $15 \mathrm{~V}$ which is given to the general-purpose inverter controller. In addition to this, block diagram of the proposed model is shown in Fig. 3.

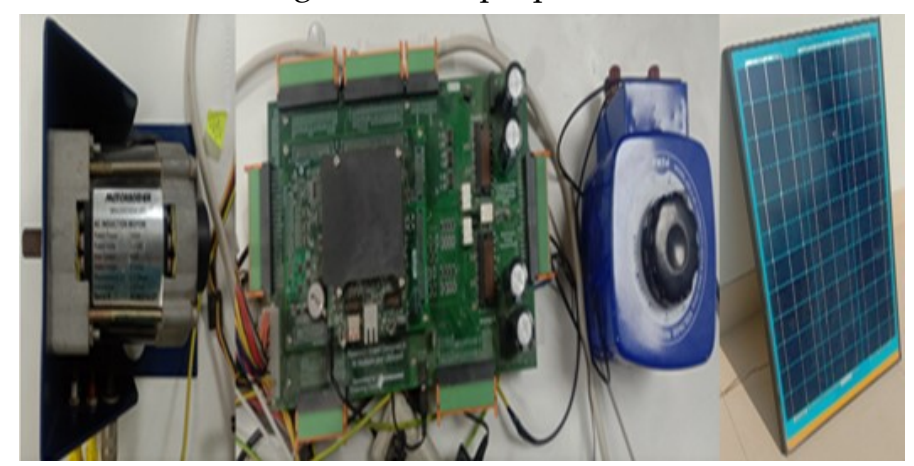

Figure 2. Experimental setup of the model

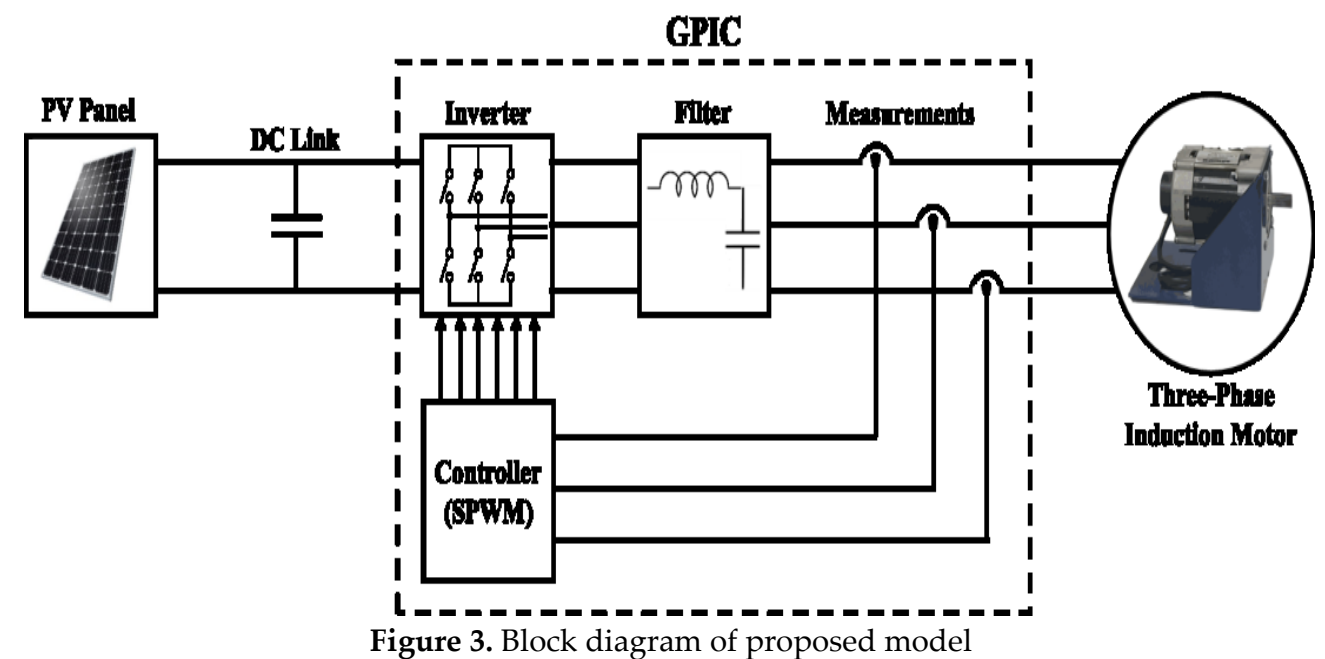

\footnotetext{
${ }^{1}$ National Instruments. Available online: https://decibel.ni.com/content/docs/DOC-19212 (accessed on 15th July 2020).

2 NI sbRIO Evaluation Kit by National Instruments. Available online: https://decibel.ni.com/content/thread/16214 (accessed on 25th July 2020).
} 
Three phase induction motor parameters used in this study along with its rating are represented in table 1.

Table 1. Three phase induction motor parameters

\begin{tabular}{|l|l|}
\hline Parameters & Ratings \\
\hline Rated Power & 120 watts $(\mathrm{W})$ \\
\hline Rated Voltage & 30 Volt AC (VAC) \\
\hline Maximum Speed & 4000 RPM (Revolutions per minute) \\
\hline Rated Current & 6 Amperes $(\mathrm{A})$ \\
\hline Resistance (L-L) & 0.7 Ohms $(\Omega)$ \\
\hline Inductance & 2.27 Milli Henry $(\mathrm{mh})$ \\
\hline
\end{tabular}

\section{Co-Simulation with Multisim and LabVIEW}

This is the approach against obtaining goal of regulating the speed of three phase induction machine, this also require proper modelling and responses of the system. Multisim and LabVIEW are the best tools to perform co-simulation and get results of the model. To empower the progress of power electronic control IP for LabVIEW FPGA, it can be quite helpful.

Multisim and LabVIEW are quite supportive while performing nonlinear analysis in cosimulation, sharing reports at the end of every other time step. These both will manage potential time steps once LabVIEW is enabled to utilize variable phase size solver, culminating in a fully designed and precise model. Accuracy is the major concern in both tools while measuring the results. Selection of step size plays crucial role while analysing the behaviour of three phase induction motor because there are there is inrush current due to start and stop of induction motor. If large step size is selected, this may cause inappropriate results depending upon the type of control action. Thus, it becomes mandatory for a designer, to choose the proper step size in order to achieve proper results. Fig. 4 represents the co-simulation of three phase induction motor along with a LabVIEW control [17].

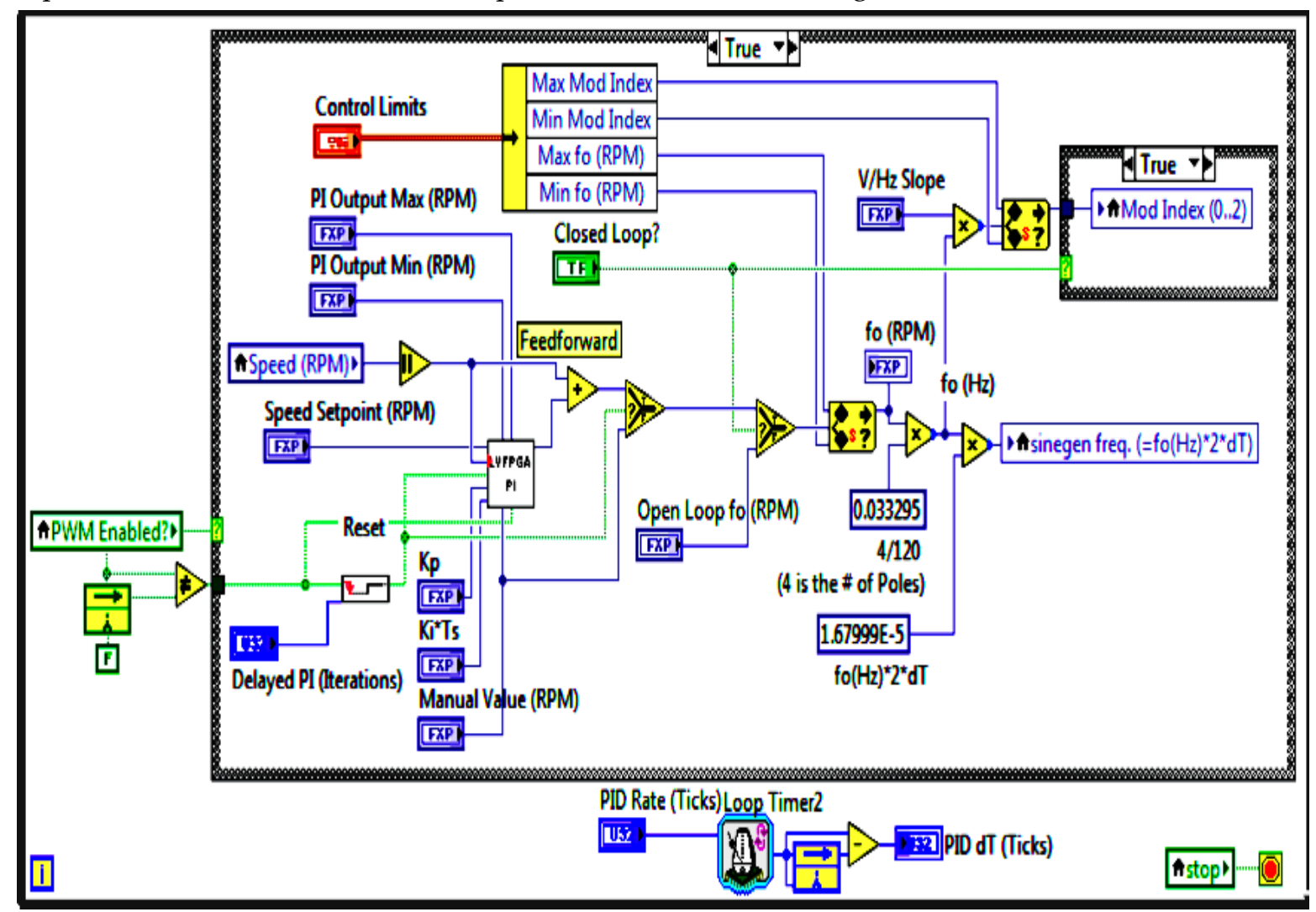

Figure 4. Co-simulation with V/f Control implementation [17]

\subsection{LabVIEW GUI for V/F Control}

Fig. 4 entails the details of control executed. Enabling of module plays important role and with this case structure is enabled. After enabling, there is a Boolean switch and the function of this switch 
is to check either setting of control is in manual mode or in automatic mode. When the setting is in automatic mode there is a block named as LabVIEW Field Programmable Gate Array (LVFPGA), which is triggered and achieves various values of parameters like $\mathrm{Kp}, \mathrm{Ki}$ and speed to set up points for feedback control. There is also a selector switch and the function of this switch is to pick up the value from LVPFGA block automatically rather than manually. The wave which appears at the output is sine gen frequency.

\subsection{Design of SPWM controller in MATLAB}

In Fig. 5 SPWM generator, three phase inverter circuit and Filter circuit with resistive load are shown. PWM generator generates three phase voltages which are 1200 far from each other. Now comparison is carried out at higher carrier frequency in order to generate gate pulses. This is shown in Fig. 6 and Fig. 7 respectively. Apart from this, SPWM generates gate pulses which are then applied to IGBT. Output of inverter is illustrated in Fig. 8, which is without filter and with LC filter is shown in Fig. 9 consecutively

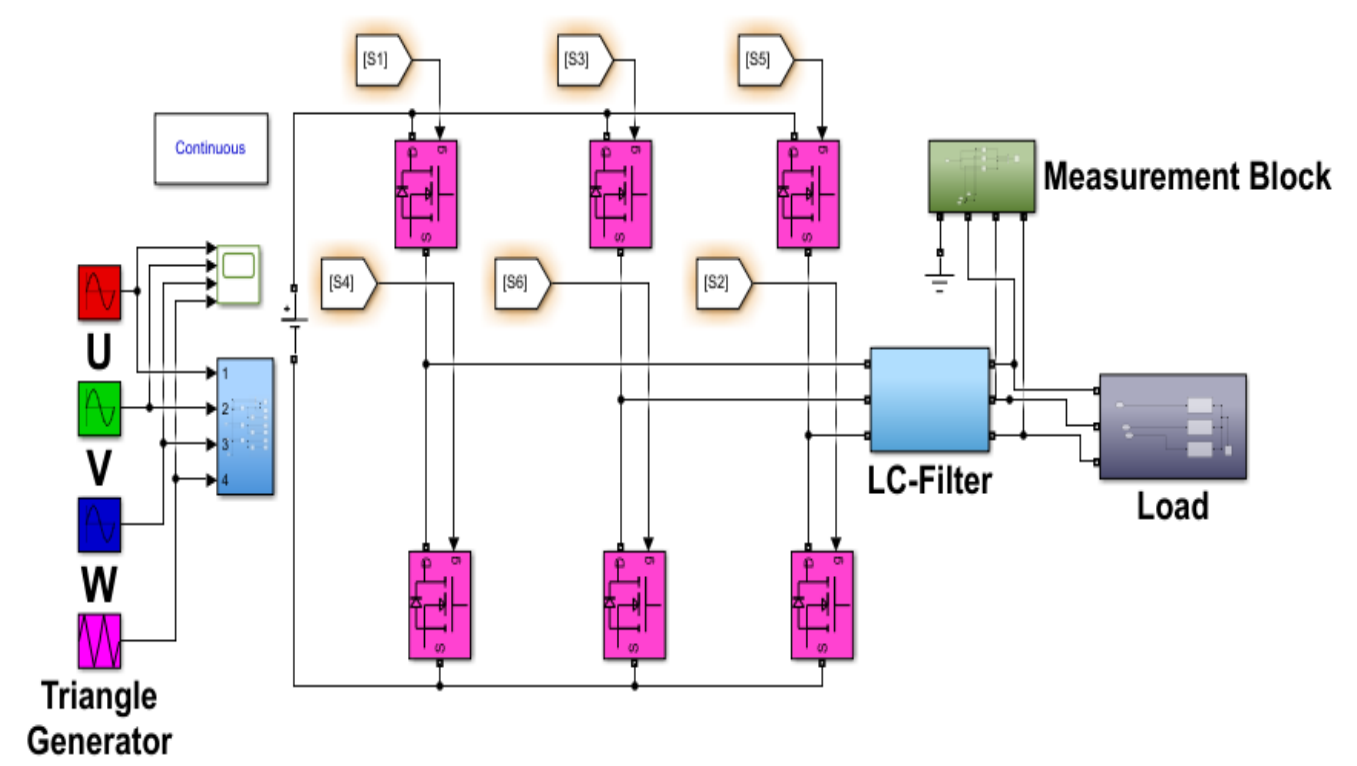

Figure 5. MATLAB Simulink model
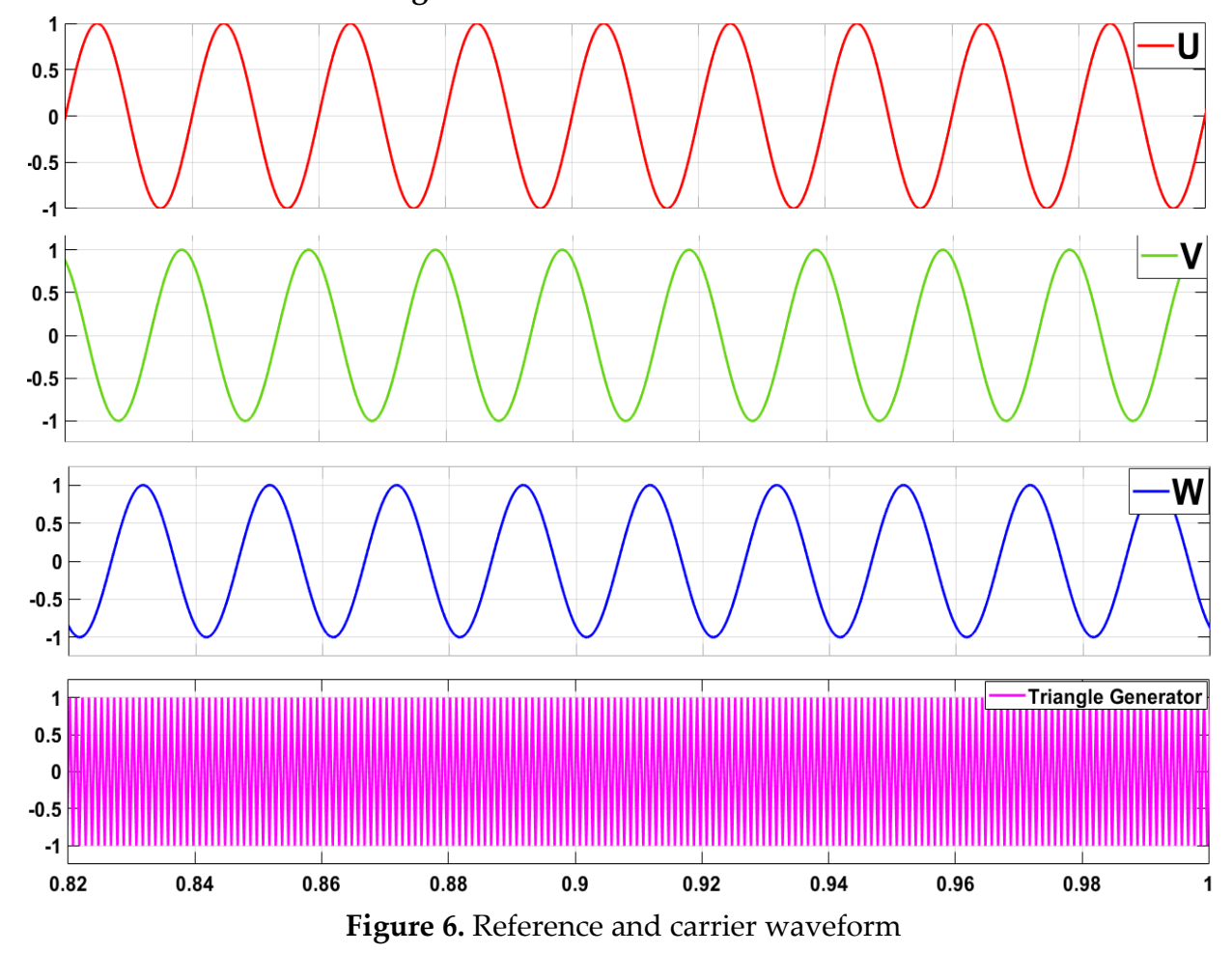

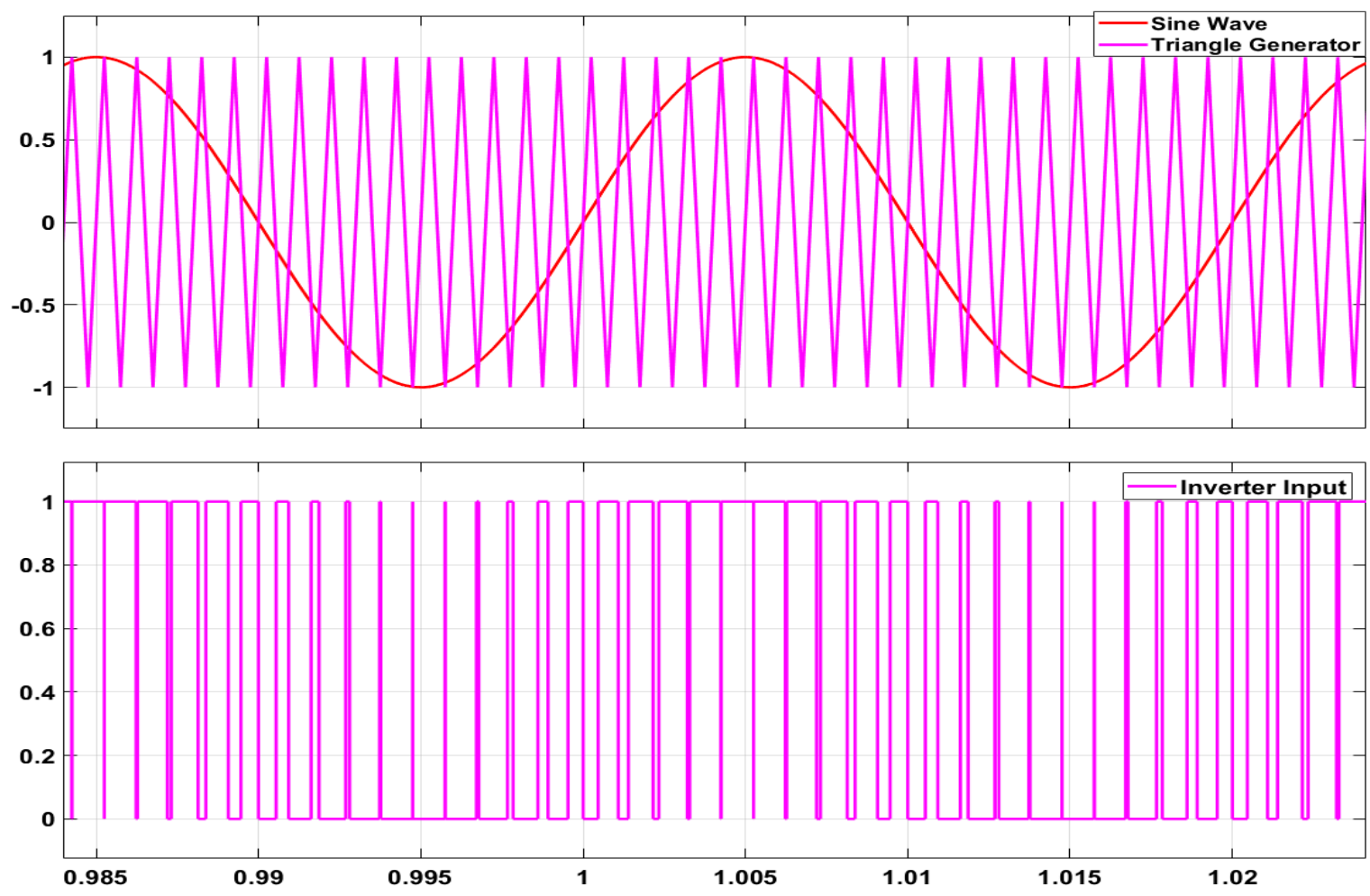

Figure 7. Input and output from the comparator
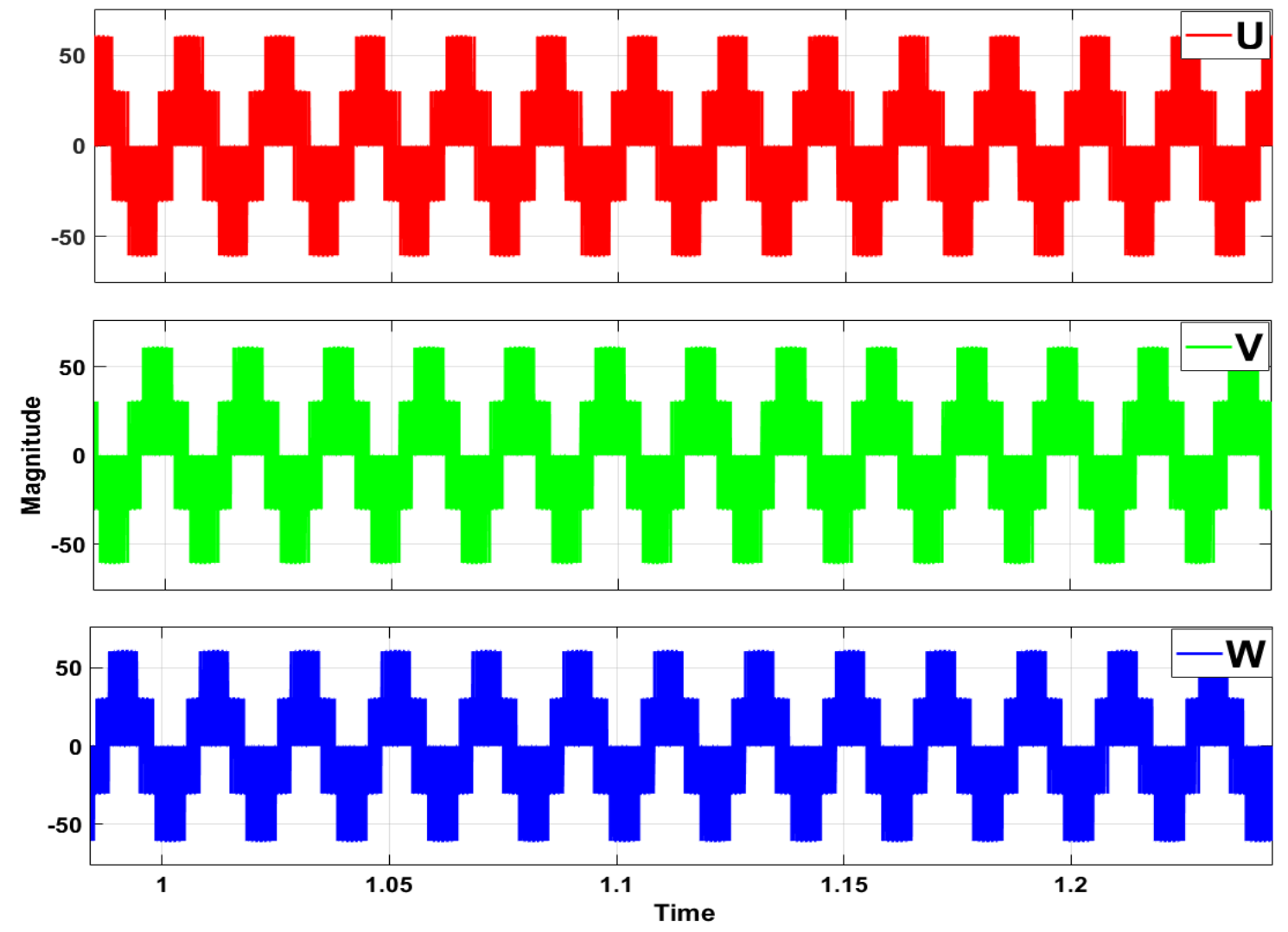

Figure 8. Three-phase output voltages without filter

It can be seen from Fig.8 that three phase output voltage waveforms of the inverter contain a lot of unwanted signals i.e., harmonics which are mitigated with the help of LC filter and smooth three phase sinusoidal output wave forms are achieved as shown in Fig. 9 


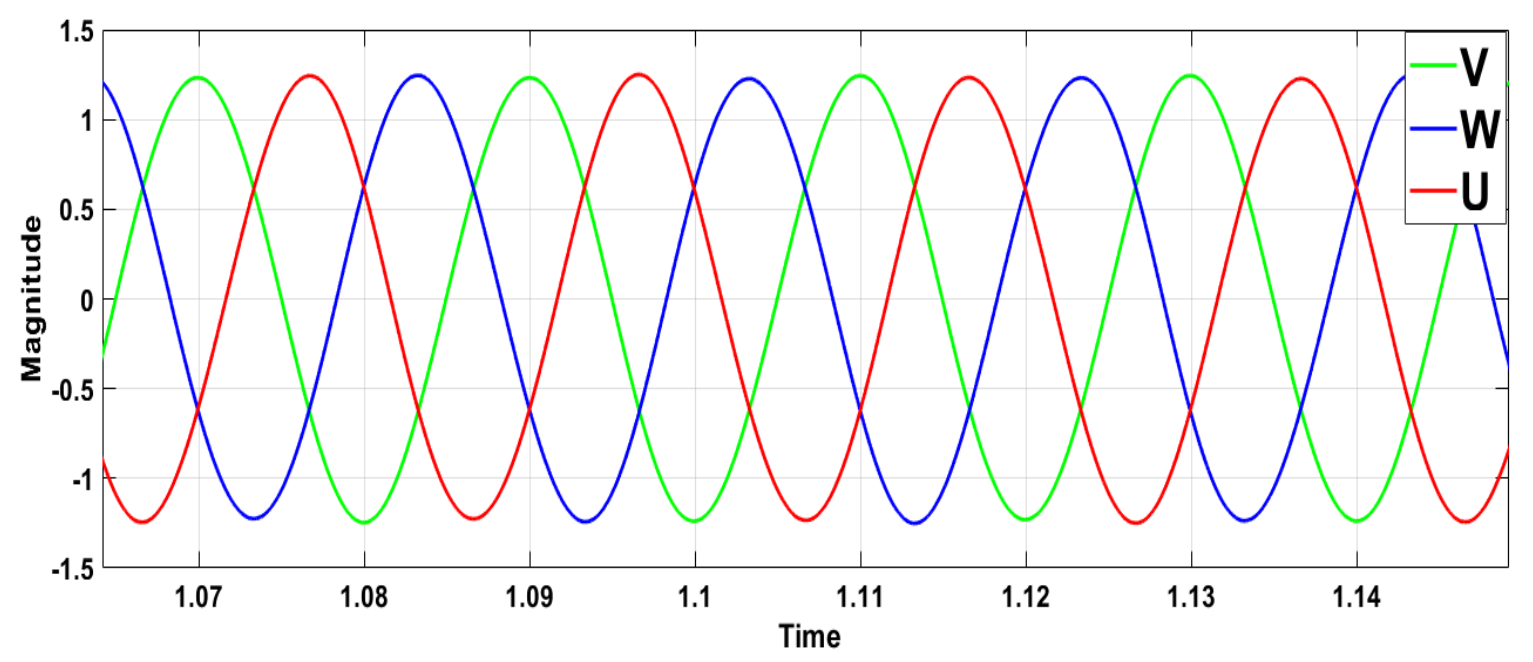

Figure 9. Three-phase output voltages with filter

\section{Results and Discussion}

\subsection{Open loop control in 3-phase induction machine}

In this portion main objective is to analyse PWM vector which is accomplished by the comparison of two waves, i.e., sine and triangular wave. Frequency for open loop is settled at 2000 Hz. PWM vector and PWM time checked in this research is 32.37 and 253.05 seconds. Moreover, the amplitude of the three phase voltages is almost the same as shown in Fig. 10.

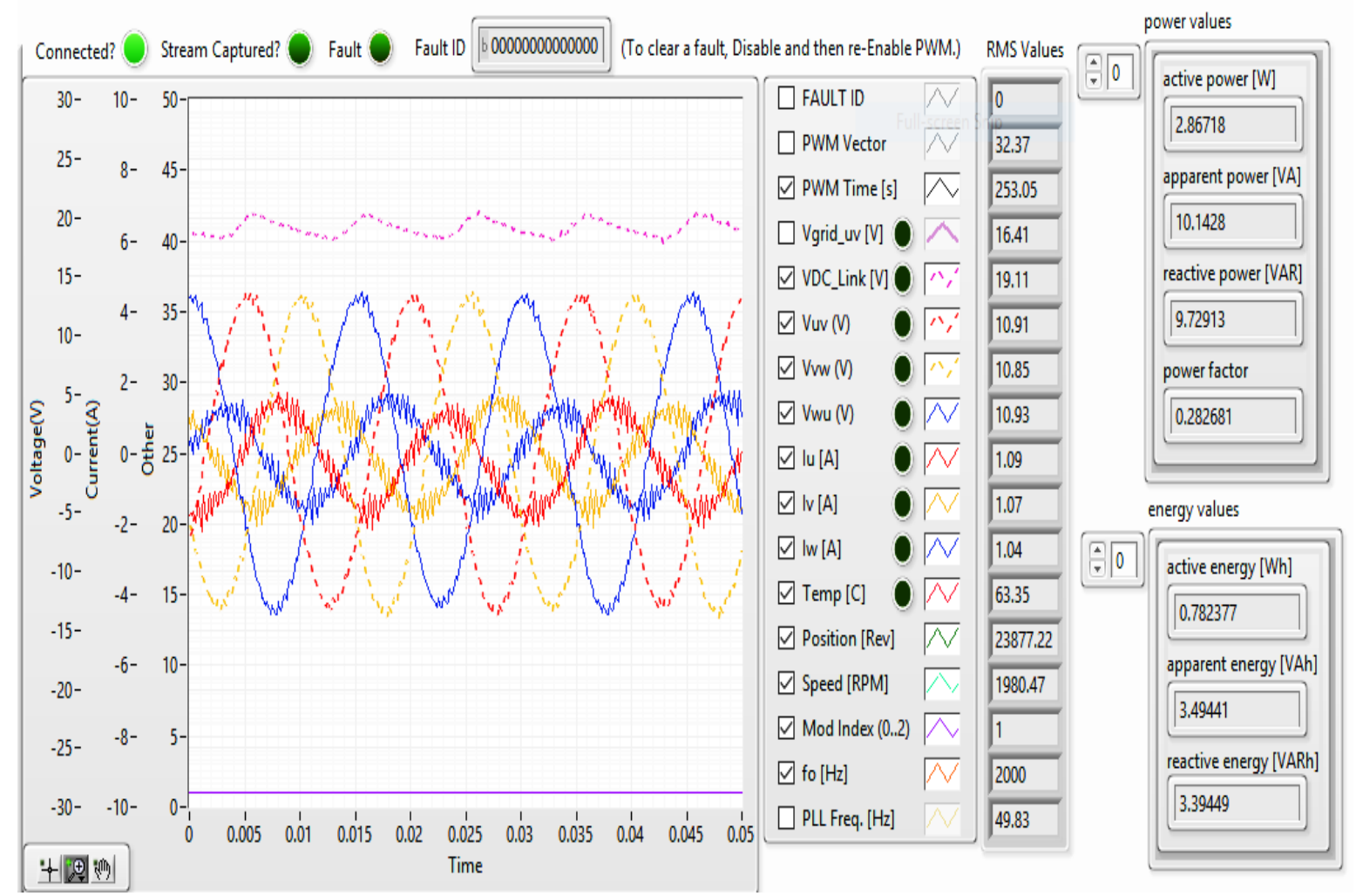

Figure 10. Output Waveforms

\subsection{Impact of carrier frequency on Various Parameters}

The carrier frequency plays a significant role in the overall performance of inverter. Power quality is affected at declined carrier frequencies and contains unwanted variations in the voltage and current. By increasing the carrier frequency, a good chunk of harmonics is removed on one hand and also power quality is improved on the other hand. However, increased carrier frequency also 
results in considerable switching losses which are a drawback. It is also observed that at lower carrier frequency the temperature of IGBT is low, but when frequency is increasing the temperature also rises.

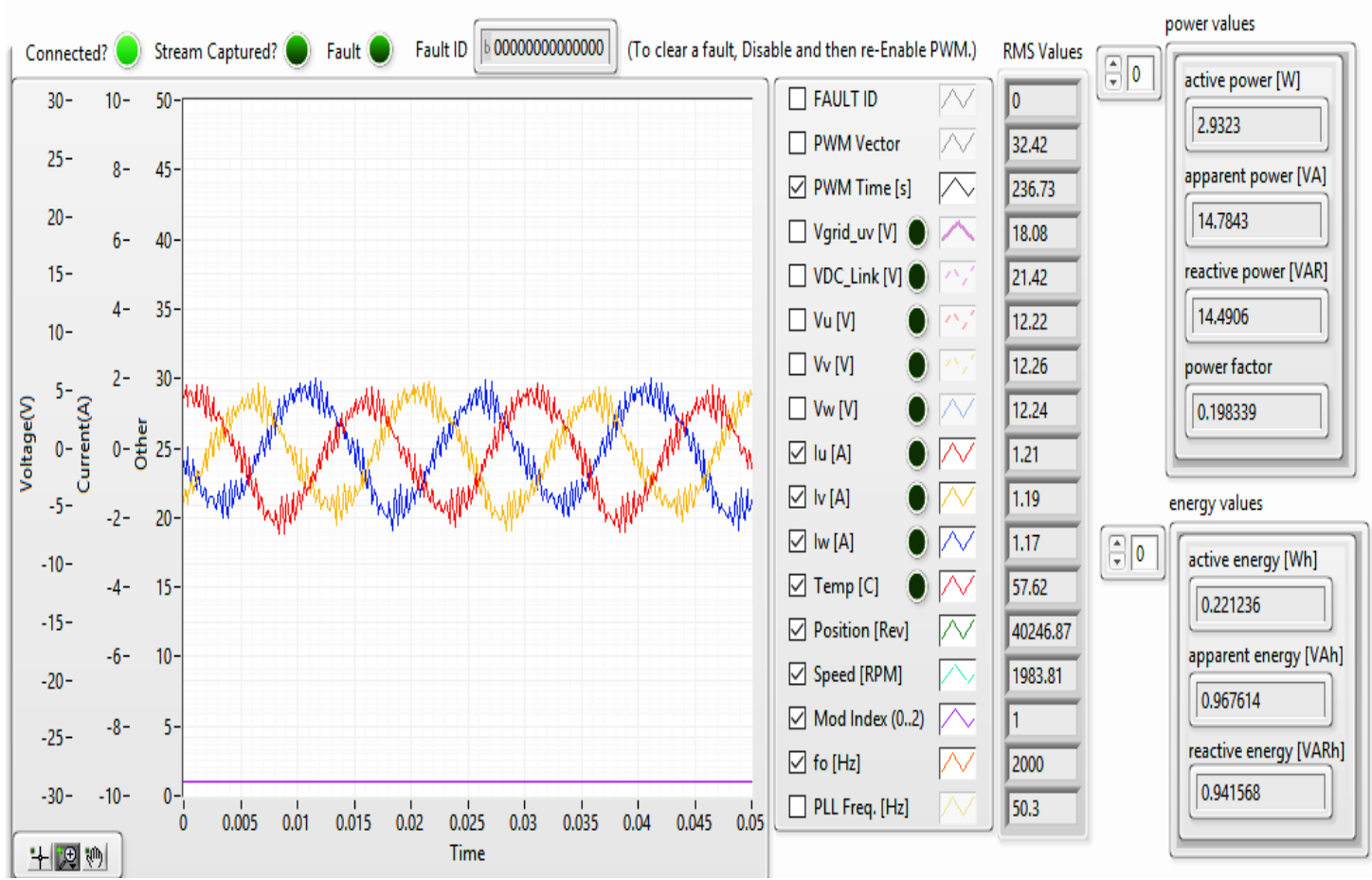

Figure 11. Output parameters at carrier frequency of $2000 \mathrm{~Hz}$
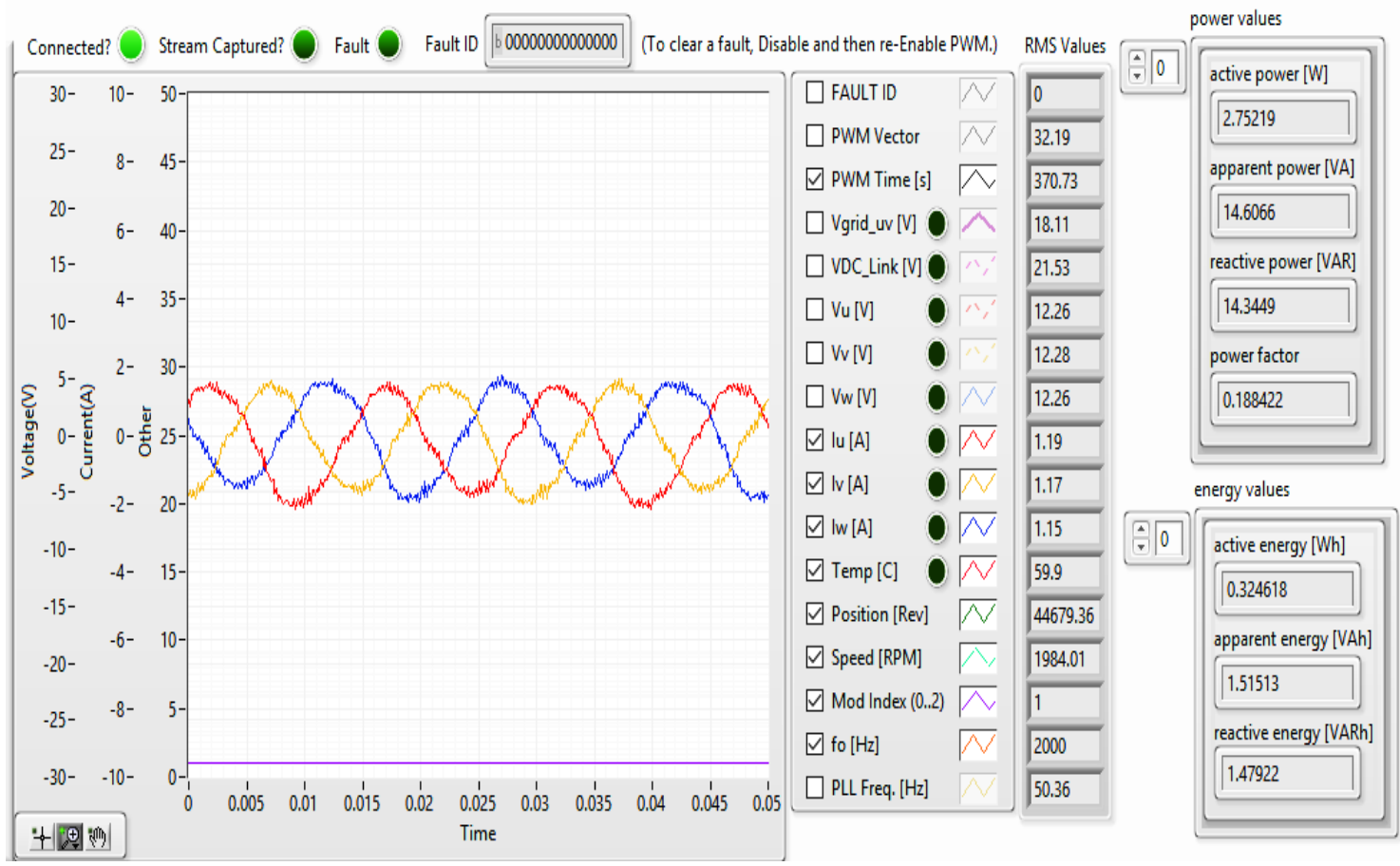

Figure 12. Output parameters at carrier frequency of $7000 \mathrm{~Hz}$

The effect of carrier frequency on different parameters can be seen in Fig. 11 and Fig. 12. Carrier frequency is kept $2000 \mathrm{~Hz}$, ripples are observed in three phase currents and $57.62^{\circ} \mathrm{C}$ temperature is analysed but at $7000 \mathrm{~Hz}$ less ripples are observed and $59.9^{\circ} \mathrm{C}$ temperature appears. Furthermore, three phase currents UVW with small variations in magnitude like 1.19A, 1.17A, 1.15 A are perceived. There is also impact of carrier frequency on active power, reactive power, apparent power and power factor. It can be seen from Fig. 15 that when open loop frequency is increasing from $2000 \mathrm{~Hz}$ to 3000 $\mathrm{Hz}$ the value of active power, reactive power and apparent power also improves. Whereas power factor is also inclined from 0.188 to 0.510 


\subsection{Influence of modulation index}

In this research modulation index is varied from 01 to 0.7 at $2000 \mathrm{~Hz}$ open loop frequency. It is analysed that with the variations in modulation index results the increase or decrease in the amplitude of the three phase voltages. Thus, it can be said that modulation index is directly proportional to three phase voltages. It is also observed that as modulation index increases the ripples in to the output current decreases up to certain value. So, power quality is improved. Despite of that, active power apparent power and reactive power are increasing with increment in the value of modulation index, though, power factor is affected as shown in Fig. 13

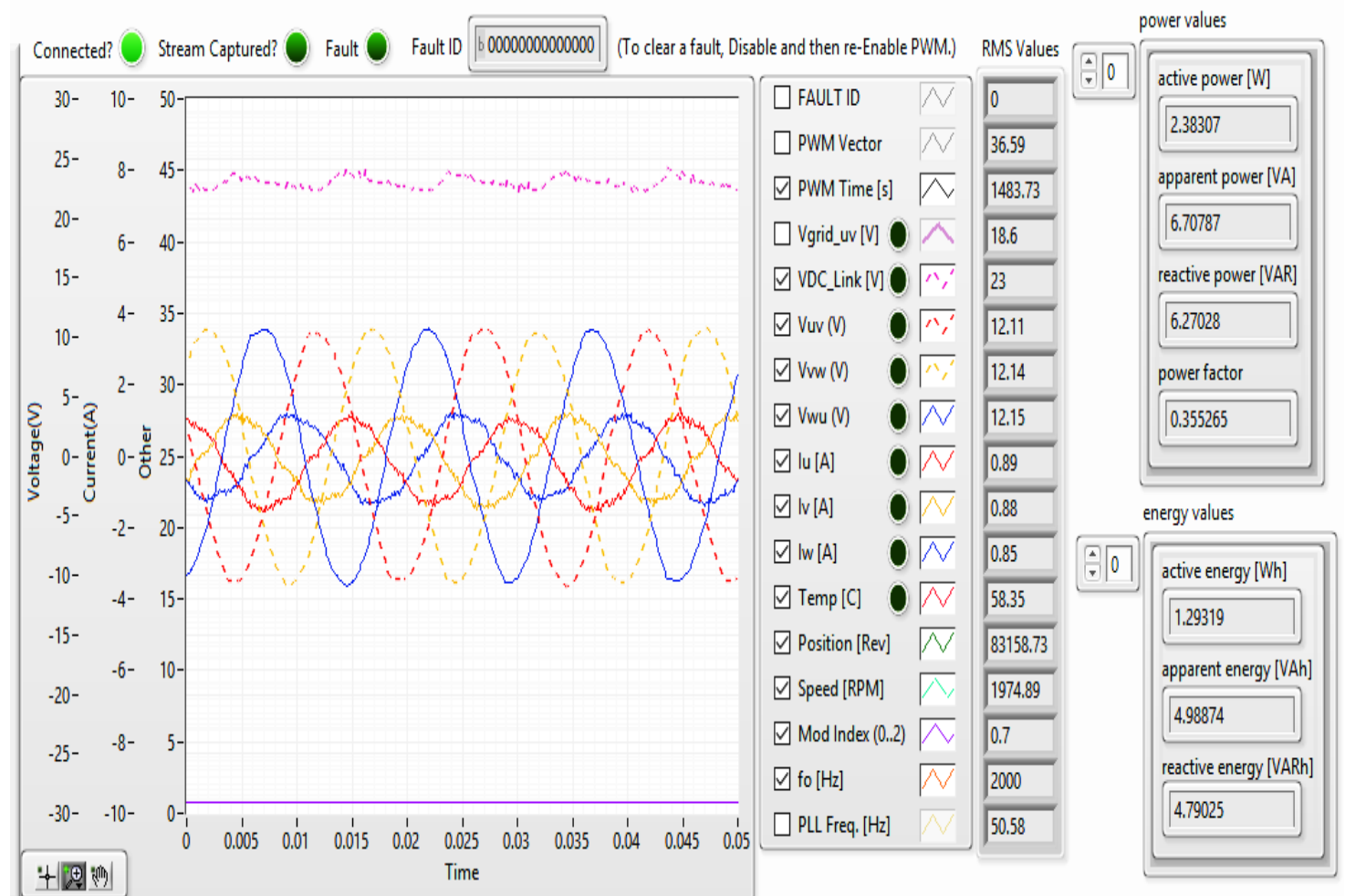

Figure 13. Experimental results at $\mathrm{m}=0.7$
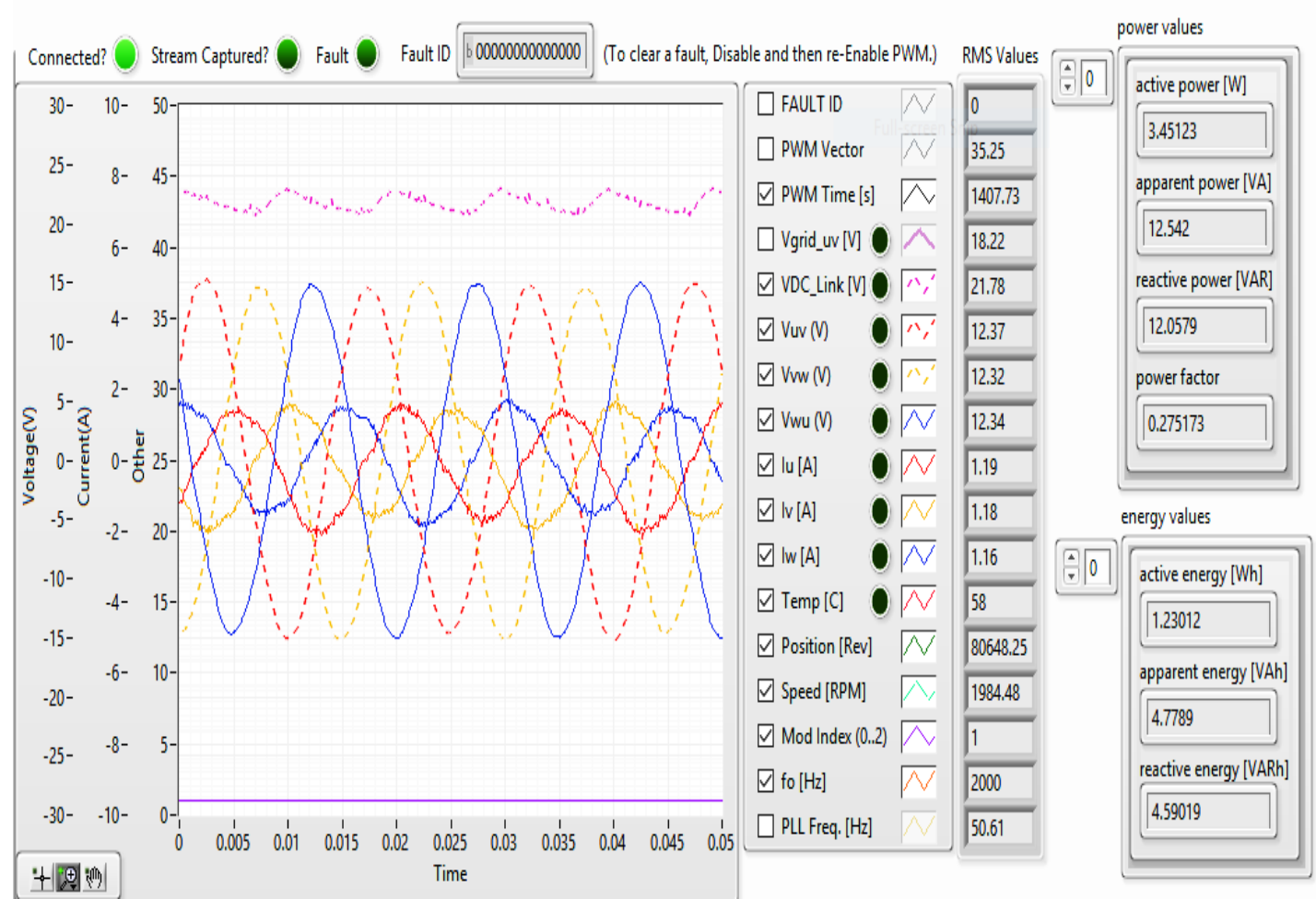

Figure 14. Experimental results at $\mathrm{m}=01$ 
It is worthwhile to note that modulation index has adverse impact on power factor, when the value of modulation index rises the power factor declines. Apart of this, temperature is also affected with variation in modulation index. Fig. 13 and Fig. 14 illustrate the impacts on parameters at different modulation indexes. When modulation index varies from 0.5 to 1 , the value of active power, apparent power and reactive power increases from $2.38 \mathrm{~W}$ to $3.45 \mathrm{~W}, 6.70 \mathrm{VA}$ to $12.54 \mathrm{VA}$ and 6.27 VAR to 12.05 VAR simultaneously. Meanwhile, power factor and temperature go down from 0.355 to 0.2755 and $58.35^{\circ} \mathrm{C}$ to $58^{\circ} \mathrm{C}$ exclusively.

\subsection{Faults in the system}

Due to sudden variation in the speed of motor, inrush current starts to flow which is not virtuous in case of motor. Therefore, motor may stop and thus it is assumed as a fault. Motor running at 3000 $\mathrm{Hz}$ is shown in Fig. 15. However, when the speed of motor is varied from $10000 \mathrm{~Hz}$ to $1500 \mathrm{~Hz}$, three phase currents are almost zero as shown in Fig. 16 and temperature is also decreasing from $60.17^{\circ} \mathrm{C}$ to $40.26^{\circ} \mathrm{C}$. Meanwhile, active power reactive power and apparent power decline to zero. In addition to this, inrush current starts to flow due to sudden variation and this is about $9.8 \mathrm{~A}$, which is illustrated in Fig. 17
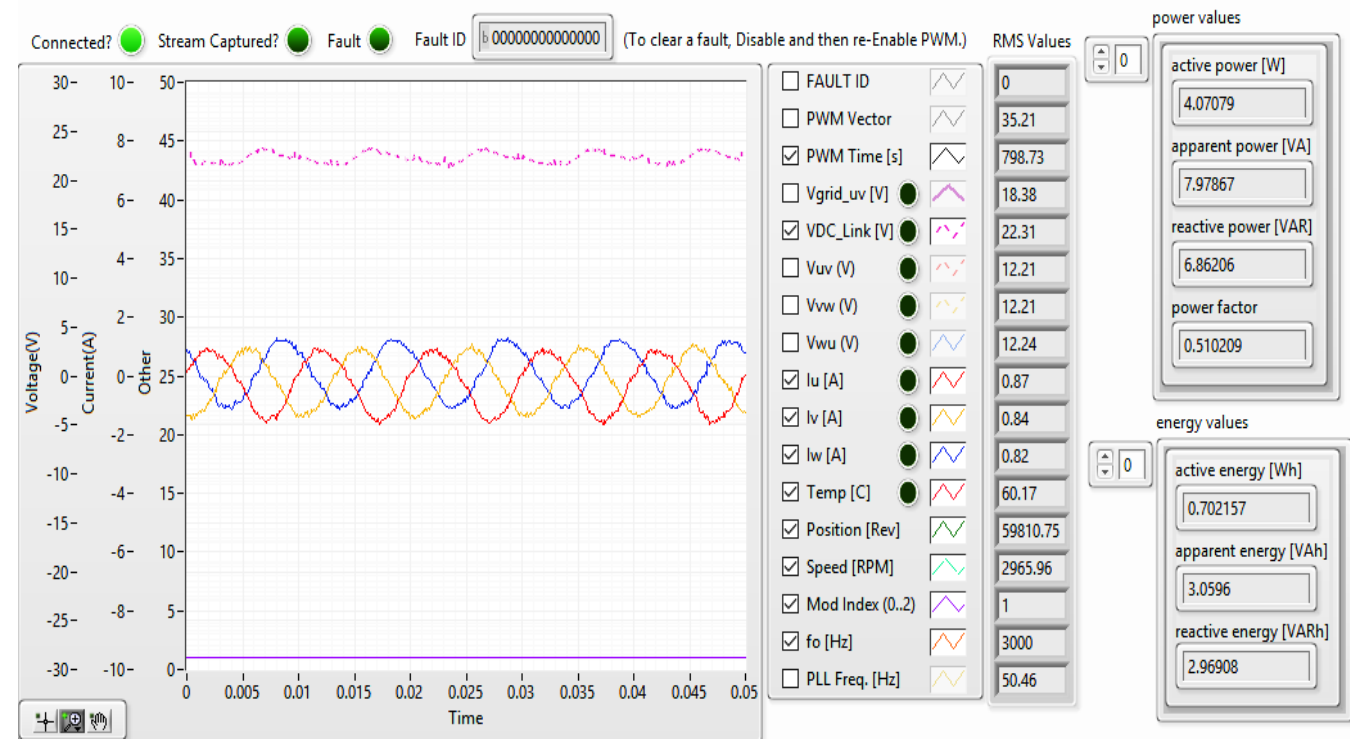

Figure 15. Normal mode of induction motor at 3000rpm
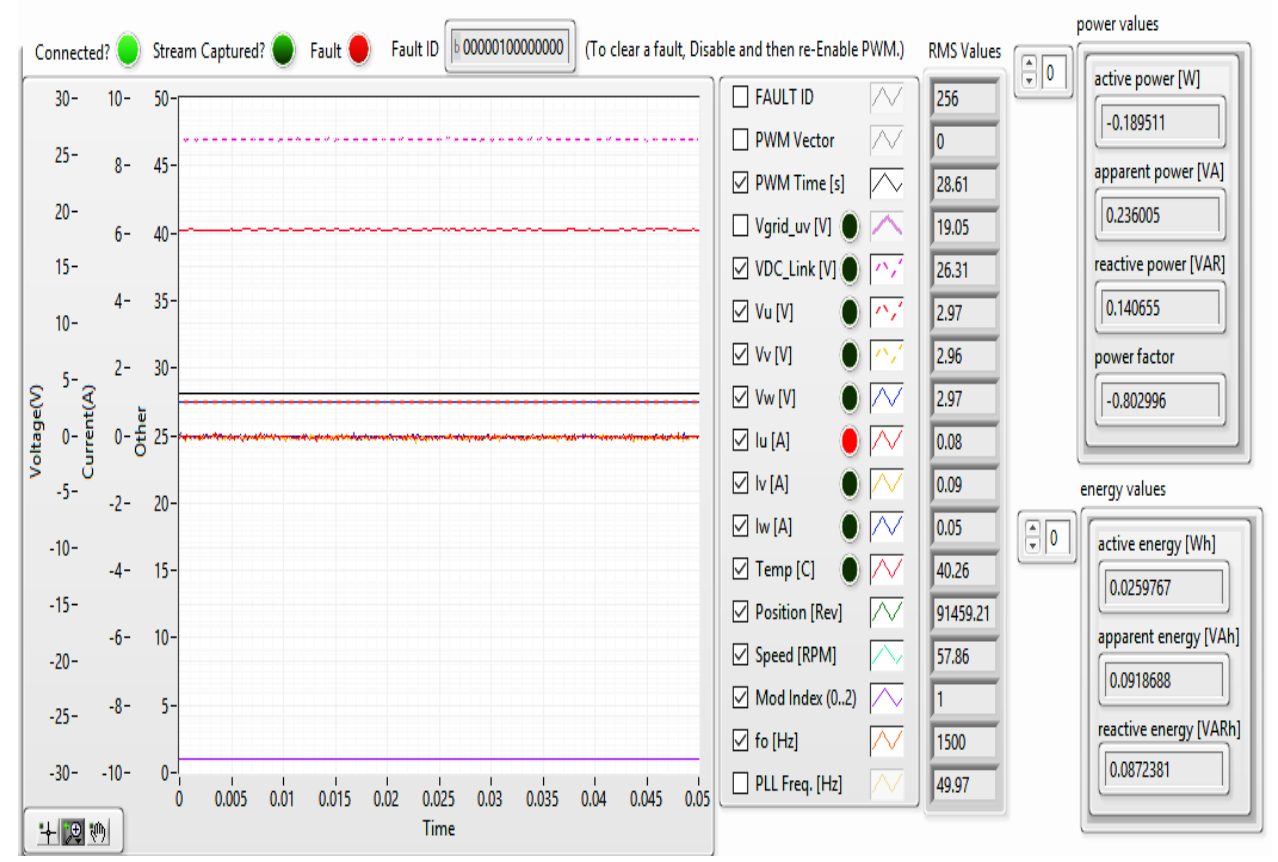

Figure 16. Fault in the system at $1500 \mathrm{rpm}$ 


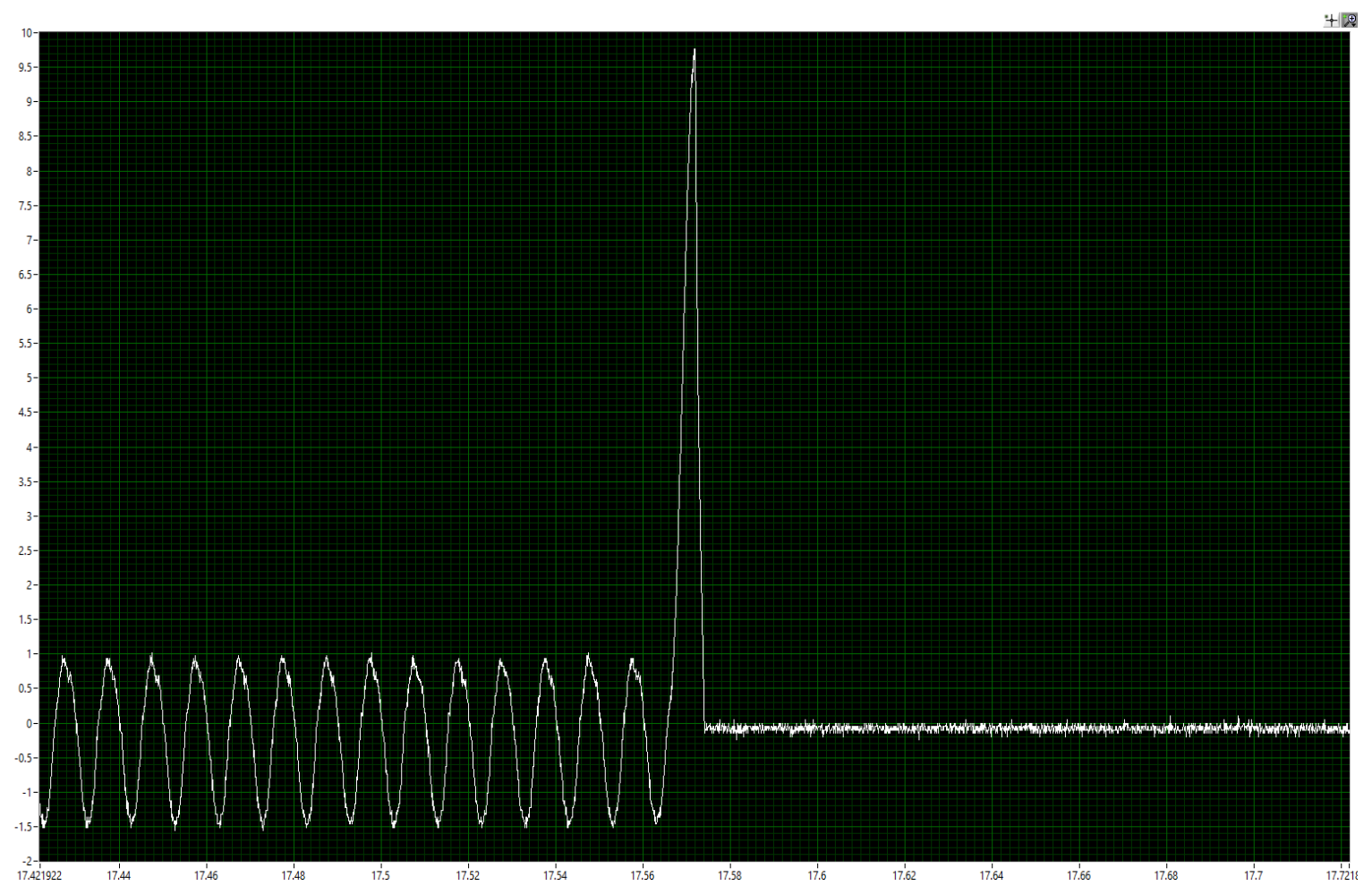

Figure 17. Inrush current due to variation in speed

\section{Conclusion}

At the end of this study, it has been examined VFD design with PWM technique adopted is the most effective way to govern the speed of three phase induction machine. This is the most suitable way where two factors are given full consideration i.e. performance and efficiency. GPIC is powered up with the help of photovoltaic panel and three phase induction motor were interfaced to take experimental results of designed control strategy on LabVIEW. Besides, it is analysed, with higher carrier frequencies power quality gets enhanced. In addition to this, impact of modulation index is also taken into account where it was observed that with values of modulation index from 0.5 to 1 power quality is improved. Modulation index have linear relation with active reactive and apparent power, however modulation index left adverse impact on power factor. It is analysed in this research that power factor decreases with the increase in modulation index up to certain value. In the end, fault induced into the system results high current overshoots and speed variation. Thus, it can be suggested to use this control strategy in developing countries where minimization of energy consumption is an essential requirement. This research work can be extended in future to calculate the switching losses which are not computed in this research.

\section{Acknowledgment}

The authors would like to acknowledge the support received from Sukkur IBA University, particularly its PHIL lab. The technical supports received from Faheem Akhtar Chachar and Umar Abdul Majeed are also acknowledged.

\section{References}

[1] Chengaiah, C. and Parsad, S. (2013). Performance of Induction Motor Drive by Indirect vector-controlled method PI and Fuzzy Controllers. International Joournal of Science, Environment, Vol.2 No.3, pp 475-469, Available: https://citeseerex.ist.psu.edu/viewdoc/download?doi=10.1.1.683.9099\&rep=rep1\&type=pdf.

[2] Mohan, N. Advanced electric drives: analysis, control, and modeling using MATLAB/Simulink. John Wiley \& Sons; Inc., Hoboken, New Jersey, Canada, 2014, pp 108-109, ISBN: 978-1-118-48548-4.

[3] Lakshmi, N. S; Adhavan, B; Jagannathan, V. and Ravichandran, C. S. (2013, March). Reduction of transient and steady state speed pulsation in permanent magnet synchronous motor using Space Vector Pulse Width 
Modulation control, International Conference on Circuits, Power and Computing Technologies (ICCPCT), Nagercoil, India; 2013, March, pp. 252-257.

[4] Yi, H.; Zhuo, F.; Zhang, Y.; Li, Y.; Zhan, W.; Chen, W. and Liu, J. (2013). A source-current-detected shunt active power filter control scheme based on vector resonant controller. IEEE Transactions on industry applications, Vol. 5 No. 3, pp 1953-1965, Available: https://www.semanticscholar.org/paper/A-SourceCurrent-Detected-Shunt-Active-Power-Filter-Yi-Zhuo/bc0fa9eaeea2146c3999a54ff93f53d0bbf5a64e.

[5] Behera, P. K.; Behera, M. K. and Sahoo, A. K. (2014). Comparative Analysis of scalar \& vector control of Induction motor through Modeling \& Simulation. International Journal of Innovative Research, Electronics, Instrumentation and Control Engineering (IJIREEICE), Vol.2 No. 4, pp 1340-1344, Available: https://ijireeice.com/wp-content/uploads/2013/03/IJIREEICE1A-a-pabitra-kumar-Comparative-Analysisof-scalar.pdf.

[6] Arulmozhiyal, R. and Baskaran, K. (2009). Space Vector Pulse Width Modulation Based Speed Control of Induction Motor using Fuzzy PI Controller. International Journal of Computer and Electrical Engineering (IACSIT), Vol. 1 No.1, pp 98-103, Available: http://pdfs.semanticscholar.org/b8af/ 2bb1db c3e42 c67afb4 d09c2db.

[7] Shirke, M. D.; Haripriya, M. and Kulkarni, H. (2013). Microcontroller based speed control of three phase induction motor using v/f method. International Journal of Scientific and Research Publications (IJSRP), Vol. 3 No. 2, pp 1-6.

[8] Hassan, S. U. and Akram, H. B. Speed and frequency control of ac induction motor using variable frequency drive. Student Research Paper Conference, Institute of Space and technology, Pakistan, 2015, pp. 272-279.

[9] Abid, E. G.; Shaikh, E. S. A.; Shaikh, E. M. F.; Rajput, E. S. H.; Majeed, E. U. A. and Shaikh, E. A. M. IOT based Smart Industrial panel for controlling Three-phase Induction motor, Third International Conference on Computing, Mathematics and Engineering Technologies, Sukkur IBA, Pakistan, 2020, January, pp. 1-8.

[10] Aditya, T. (2013). Research to study variable frequency drive and its energy savings. International Journal of Science and Research (IJSR), Vol. 2 No. 6, pp 253-256, Available: https://www.ijsr.net/archive /v2i6/ IISRON12013152.pdf.

[11] Coetzer, B. and Gouws, R. Design of a PLC-Based Variable Load, Speed Control System for a Three-Phase Induction Motor. Power Engineering Conference, Southern African Universities, South Africa, 2016, January, pp. 318-324.

[12] Razaque, F.; Soomro, N.; Samo, J. A.; Dharejo, H. and Shaikh, S. (2017). Analysis of Home Energy Consumption by K-Mean. Annals of Emerging Technologies in Computing (AETiC), Vol. 1, No. 1 pp 1-6, Available: https://www.academia.edu/34738682/Analysis of Home Energy Consumption by K Mean.

[13] Pachpande, S. and Zope, P. H. (2012). Studying the effect of shading on Solar Panel using MATLAB. International Journal of Science and Applied Information Technology, Vol. 1 No. 2, pp 2278-3083, Available: https://www.semanticscholar.org/paper/Studying-the-effect-of-shading-on-Solar-Panel-using-PachpandeZope/6cdfd28ab97eec61d57b0e79fdd0cd4b0b4fe386.

[14] Teo, J. C.; Tan, R. H.; Mok, V. H.; Ramachandaramurthy, V. K. and Tan, C. (2018). Impact of partial shading on the PV characteristics and the maximum power of a photovoltaic string. Energies, Vol. 11 No. 7, pp 1860, Available: https://doi.org/10.3390/en11071860.

[15] Chattal, M.; Bhan, V.; Madiha, H. and Shaikh, S. A. Industrial automation and control through PLC and LabVIEW, Second International Conference on Computing, Mathematics and Engineering Technologies, Sukkur IBA, Pakistan, 2019, January, pp. 1-5.

[16] Purnata, H; Rameli, M. and AK, R. E. (2017). Design of Three Phase Inverter Using Hysteresis Space Vector Pulse Width Modulation for Speed Control Three Phase Induction Motor. Journal of engineering and higher technology (JEHT), Vol.3 No.1, pp 1-10.

[17] Surti, A. Speed control of induction motor using FPGA based NI-GPIC board, Master of Science in electrical engineering, California State University, Northridge. 2015, December.

(C) 2020 by the author(s). Published by Annals of Emerging Technologies in Computing (AETiC), under the terms and conditions of the Creative Commons Attribution (CC BY) license which can be accessed at http://creativecommons.org/licenses/by/4.0. 